\title{
Active source monitoring at the Wenchuan fault zone: coseismic velocity change associated with aftershock event and its implication
}

\author{
Wei Yang $\cdot$ Hongkui Ge $\cdot$ Baoshan Wang $\cdot$ \\ Jiupeng $\mathbf{H u} \cdot$ Songyong Yuan $\cdot$ Sen Qiao
}

Received: 19 September 2014/Accepted: 23 October 2014/Published online: 29 November 2014

(C) The Seismological Society of China, Institute of Geophysics, China Earthquake Administration and Springer-Verlag Berlin Heidelberg 2014

\begin{abstract}
With the improvement of seismic observation system, more and more observations indicate that earthquakes may cause seismic velocity change. However, the amplitude and spatial distribution of the velocity variation remains a controversial issue. Recent active source monitoring carried out adjacent to Wenchuan Fault Scientific Drilling (WFSD) revealed unambiguous coseismic velocity change associated with a local $M_{\mathrm{s}} 5.5$ earthquake. Here, we carry out forward modeling using two-dimensional spectral element method to further investigate the amplitude and spatial distribution of observed velocity change. The model is well constrained by results from seismic reflection and WFSD coring. Our model strongly suggests that the observed coseismic velocity change is localized within the fault zone with width of $\sim 120 \mathrm{~m}$ rather than dynamic strong ground shaking. And a velocity decrease of $\sim 2.0 \%$ within the fault zone is required to fit the observed travel time delay distribution, which coincides with rock mechanical experiment and theoretical modeling.
\end{abstract}

Keywords Wenchuan fault zone - Coseismic velocity change $\cdot$ Accurately Controlled Routinely Operated Seismic Source (ACROSS) - Active monitoring · Forward modeling

W. Yang $(\bowtie) \cdot$ B. Wang $\cdot$ J. Hu $\cdot$ S. Yuan $\cdot$ S. Qiao Key Laboratory of Seismic Observation and Geophysical Imaging, Institute of Geophysics, China Earthquake Administration, Beijing 100081, China

e-mail: weiyang05@163.com

H. Ge

Unconventional Natural Gas Institute, China University of Petroleum, Beijing 102249, China

\section{Introduction}

Earthquakes are usually viewed as sudden release of stress built up in a long period seismogenic process. Laboratory experiments indicate that seismic velocities may change with the applied stress. Monitoring of the seismic velocity changes associated with earthquakes may shed light on understanding the earthquake process, and exploit the stress dependence of seismic wave velocity for analyzing the stress state of the underground media.

Since 1960s, numerous efforts have been made to measure the seismic velocity change associated with earthquakes. Prominent coseismic or pre-seismic velocity changes up to $10 \%$ were reported by different researchers (e.g., Semenov 1969; Terashima 1974), while other followup studies provided negative arguments that no detectable changes were observed in seismic velocity. However, subject to electric technology and signal process technique, velocity change with magnitude lower than $\sim 1.0 \%$ cannot be detected at the time (e.g., McEvilly and Johnson 1974; Kanamori and Fuis 1976).

With the development of seismic instrument and data processing technique, the precision of velocity change measurement has enhanced a lot during the past two decades. By comparing waveform from repeating earthquake and ambient noise before and after large earthquakes, numerous observations suggested that the coseismic velocity change was usually around $10^{-3}$ (e.g., Poupinet et al. 1984; Aster et al. 1990; Nadeau et al. 1994a, b; Haase et al. 1995; Peng and Ben-Zion 2006; Rubinstein et al. 2007; Brenguier et al. 2008; Cheng et al. 2010), which is much smaller than previously expected to be.

With the accumulation of observation supporting the coseismic velocity change, where does the velocity change occurs became another issue in debate. Cheng et al. (2010) 
observed up to $0.4 \%$ velocity in the fault zone during the $2008 M_{\mathrm{w}} 7.9$ Wenchuan earthquake in China, and they attribute the velocity to the coseismic stress release in the fault plane and adjacent rock. However, Takagi et al. (2012) revealed that the major factor affecting the velocity change was damage in shallower layers during the passing of seismic wave from the 2008 M7.2 Iwate-Miyagi Nairiku earthquake, and the effect of the static stress change might be masked by the larger effect of the strong motion.

Measurements based on natural event no matter repeating earthquake or ambient noise are subjected to the spatial and temporal distribution of those events, thus has limited spatial and temporal resolution (e.g., Cheng et al. 2010; Wang et al. 2012). Monitoring of the velocity change with artificial source is an alternative way (e.g., Yamaoka et al. 2001; Silver et al. 2007; Niu et al. 2008; Yang et al. 2010) which may shed light on where the velocity change occurs.

Recently, Yang et al. (2010) carried out a continuous velocity monitoring experiment with one Accurately Controlled Routinely Operated Seismic Source (ACROSS, e.g., Yamaoka et al. 2001; Ikuta and Yamaoka 2004; Wang et al. 2009a, b) and a $\sim 10 \mathrm{~km}$ portable seismic profile passing through the No. 3 hole of Wenchuan Fault Scientific Drilling (WFSD, e.g., Yang et al. 2012). They observed travel time delay of $\sim 4-9$ ms associated with a
$M_{\mathrm{s}} 5.5$ aftershock from the seismic stations on hanging wall of the Jiangyou-Guanxian fault, while from stations on the footwall, they did not observe any travel time delay larger than measuring error. Those observations may indicate an inhomogeneous distribution of velocity change. In this paper, we try to further investigate the spatial distribution of velocity change by forward modeling.

\section{Study region and experiment}

\subsection{Study region}

Temporal variation of stress in fault is one of the important bases to understanding the mechanism, the healing process and the developing trend of aftershocks. The Longmenshan fault zone has three main faults, which are the Maowenwenchuan fault, Beichuan-Yingxiu fault, and JiangyouGuanxian fault from west to east (Fig. 1). On May 12, 2008 a destructive earthquake with moment magnitude 7.9 stroke Wenchuan, Sichuan Province, China, which caused huge economy and life losses. This Wenchuan earthquake not only caused $\sim 350 \mathrm{~km}$ long surface rupture (e.g., Zhang et al. 2008) in Beichuan-Yingxiu fault but also induced surface deformation in the Jiangyou-Guanxian fault with a length of $\sim 80 \mathrm{~km}$ (e.g., Li et al. 2008). The

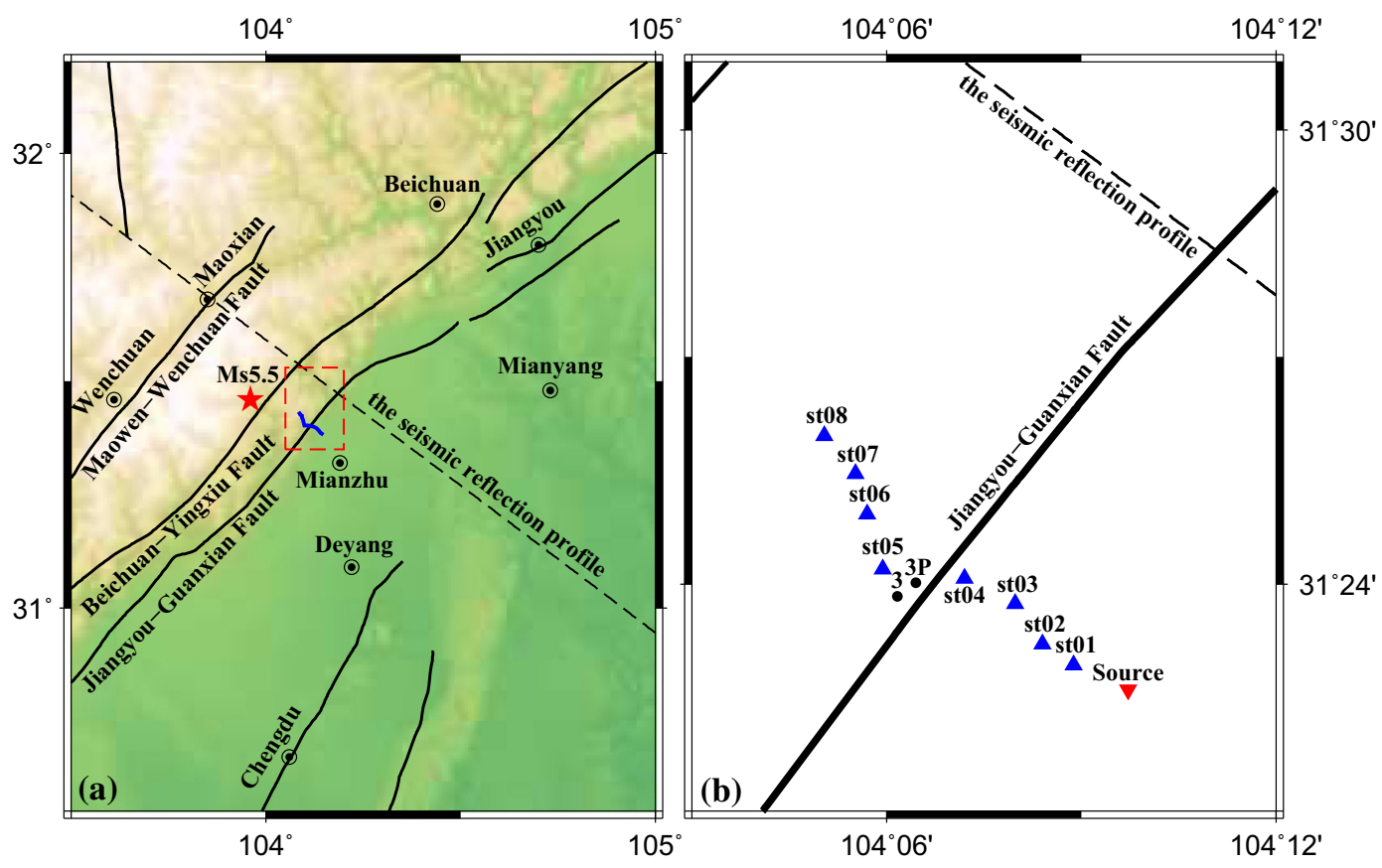

Fig. 1 a A map of the study region around the Wenchuan fault zone. The red solid square denotes the experiment site, which is further zoomed in (b). Faults and their name are indicated by solid lines and adjacent text, respectively. Dashed straight line indicates the seismic reflection profile (Xu et al. 2012). Cities are label with circled solid dot. The epicenter of $M_{\mathrm{s}} 5.5$ earthquake is marked with red star. b Detailed distribution of ACROSS (inverted red triangle) and receivers (solid triangles). Two dark dots labeled with 3 and 3P are sites of Wenchuan Fault Scientific Drilling No. 3 main hole and pilot hole, respectively 
Jiangyou-Guanxian fault is $\sim 10 \mathrm{~km}$ east to the BeichuanYingxiu fault (Fig. 1a). Jiangyou-Guanxian fault is a thrust and strike-slip fault, with a total length is about $400 \mathrm{~km}$, overall trend NE $40^{\circ}-45^{\circ}$ and the dip angle is a range from $50^{\circ}$ to $70^{\circ}$ in surface rupture, which decreases with the increase of depth (e.g., Yang et al. 2012). The stress status of Wenchuan fault zone is still in the process of healing or stress modification, which provides a good chance to carry out dynamic monitoring with active source.

\subsection{Active seismic source}

To monitor the recovery of Jiangyou-Guanxian fault after the Wenchuan earthquake, a continuous active source experiment was carried out from June 20, 2009. The experiment site is located in Jiulong town Mianzhu county, Sichuan province, China. An artificial seismic source was installed on the footwall of Jiangyou-Guanxian fault. The seismic signal radiated from the source was recorded by a seismic profile composed of eight seismic stations. The seismic profile vertically crosses the Jiangyou-Guanxian fault at the site of WFSD No. 3 hole (Fig. 1b), where $4 \mathrm{~m}$ vertical uplift induced by the Wenchuan earthquake was evidenced.

ACROSS (e.g., Yamaoka et al. 2001; Ikuta and Yamaoka 2004) was laid at the east side of the JiangyouGuanxian fault, about $5.2 \mathrm{~km}$ far away, and used as seismic source in the experiment (Fig. 2). The ACROSS is used to generate a sweeping centrifugal vertical force by two same eccentrics rotating in the opposite direction along the same horizontal axis, and emit elastic waves. The scanning frequency band ranges from 2 to $10 \mathrm{~Hz}$. When the rotational

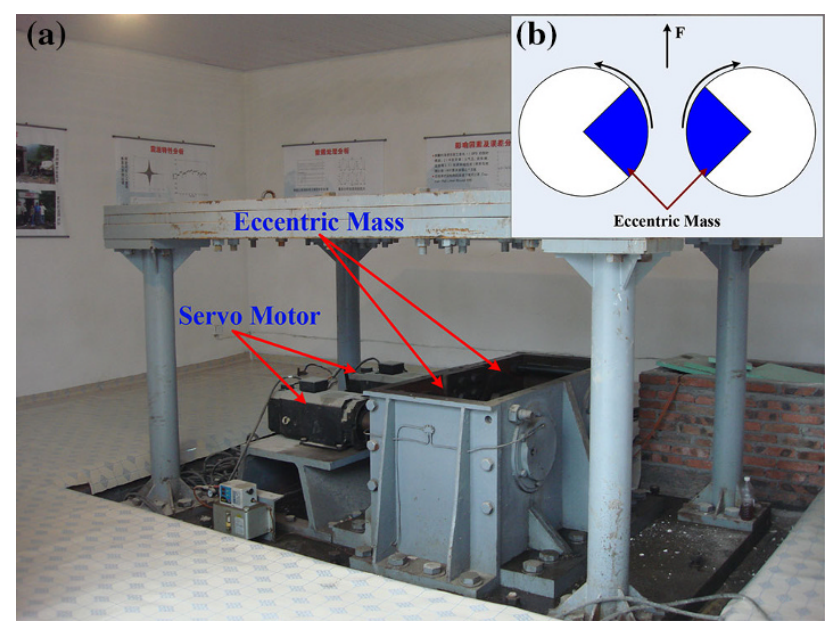

Fig. 2 a The equipment of an ACROSS. b The seismic signal excitation mechanism of the ACROSS. Two eccentric masses are driven by a pair of $15 \mathrm{KW}$ servo motors with phase feedback controller and rotating in the opposite directions, which generate a sinusoidal vertical force up to $1.0 \times 10^{5} \mathrm{~N}$ in the vertical direction speed is of ten revolutions per second, the vibration source can generate $\sim 10^{5} \mathrm{~N}$ in the vertical direction, and the scanning signal has some features such as: low frequency, narrow frequency band, and the excitation energy in the quadratic relationship with the scanning frequency (e.g., Ikuta and Yamaoka 2004; Alekseev et al. 2005; Yang et al. 2010, 2013).

\subsection{The logging system}

The recording system consists of Guralp-40T short period seismometer and RefTek-130B recorder. The sensors have sensitivity of $2,000 \mathrm{~V} \mathrm{~m}^{-1} \mathrm{~s}^{-1}$ and flat frequency response from $0.5(2 \mathrm{~s})$ to $100 \mathrm{~Hz}$, and the sampling rate of data logger was set to 200 samples per second. The working time of ACROSS and recorders is accurately and continuously controlled by synchronization to the GPS clock.

\subsection{Field experiment and observed coseismic velocity change}

The experiment was carried out from June 20, 2009 to April 20, 2012, and the portable seismic stations was set up from st02 to st07 (Fig. 1b) during the period from June 20, 2009 to August 10, 2009. The seismic source was operated daily with $\sim 10$ sweeps from $21 \mathrm{pm}$ to $02 \mathrm{am}$ at local time. During each sweep, the source was accelerated from 2 to $10 \mathrm{~Hz}$ and then down to $2 \mathrm{~Hz}$ within $26 \mathrm{~min}$. The sweeping seismic signal can be compressed into ordinary seismogram with some well-developed techniques (e.g., Yang et al. 2013), such as: cross-correlation, water level deconvolution, and coherence. Water level deconvolution is adopted in this paper. Please refer to Yang et al. (2010) for more detail about experiment setting up and source operation.

There was a bunch of local seismicity during the period of the experiment. One of the prominent events was the $M_{\mathrm{s}} 5.5$ aftershock occurred on June 30, 2009 (Fig. 1a), which was the biggest aftershock in the observation area during the active source detecting experiment. In order to measure the subtle changes of seismic velocities caused by this earthquake, the each portable seismic recording was deconvoluted with the reference signal observed near the ACROSS, then band pass filtered with $2-12 \mathrm{~Hz}$ Butterworth filter, and further stacked to enhance the signal to noise ratio (SNR). By comparing the seismic records before (stack from June 22 to June 28) and after (stack from June 30 to July 7) this earthquake, Yang et al. (2010) reported an observation of coseismic velocity change associated with this earthquake. For completeness, the observed apparent travel time changes are re-plotted in Fig. 3. 

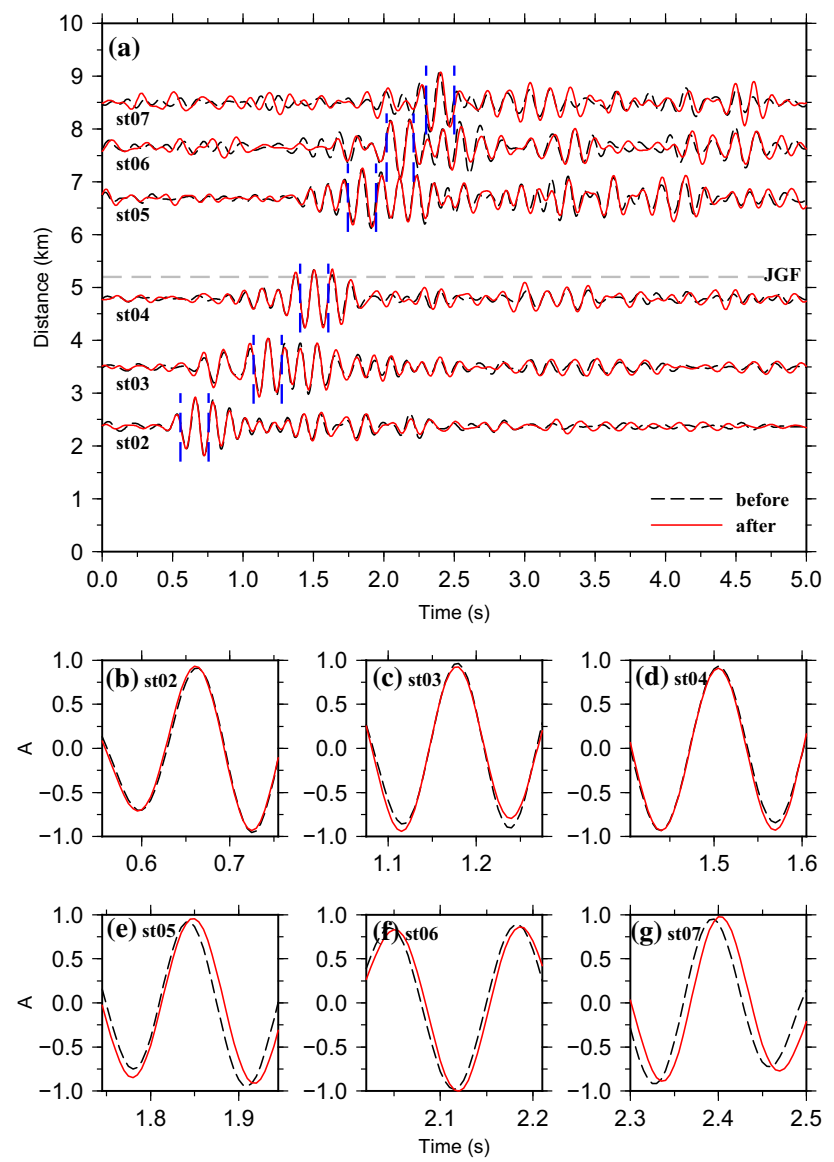

Fig. 3 a The travel time profile observed by comparing the seismic signal from the ACROSS before and after $M_{\mathrm{s}} 5.5$ earthquake (Yang et al. 2010). b-g The zoomed graph between two vertical blue lines in (a). Note that the travel time delay varies abruptly from the footwall stations to the hanging wall stations

There are three main features about the observation (e.g., Yang et al. 2010): (1) a prominent travel delay was observed for station located on hanging wall (st05, st06, and st07); (2) no travel time delay larger than the measuring error was observed from footwall stations (st02, st03, and st04); and (3) the coseismic delay measured from the hanging wall station varies from 4 to $9 \mathrm{~ms}$ under the precision $\sim 0.4 \mathrm{~ms}$.

\section{Forward modeling}

Since coseismic travel time delay was observed from one source and one side receiver, we are unable to estimate the spatial distribution of velocity change with traditional 2-D or 3-D inversion. Forward modeling on the other hand may put some constraints on the volume where the velocity is most likely to occur. Rohrbach et al. (2013) took similar forward modeling approach and studied possible surface wave dispersion variations associated with the seismogenic
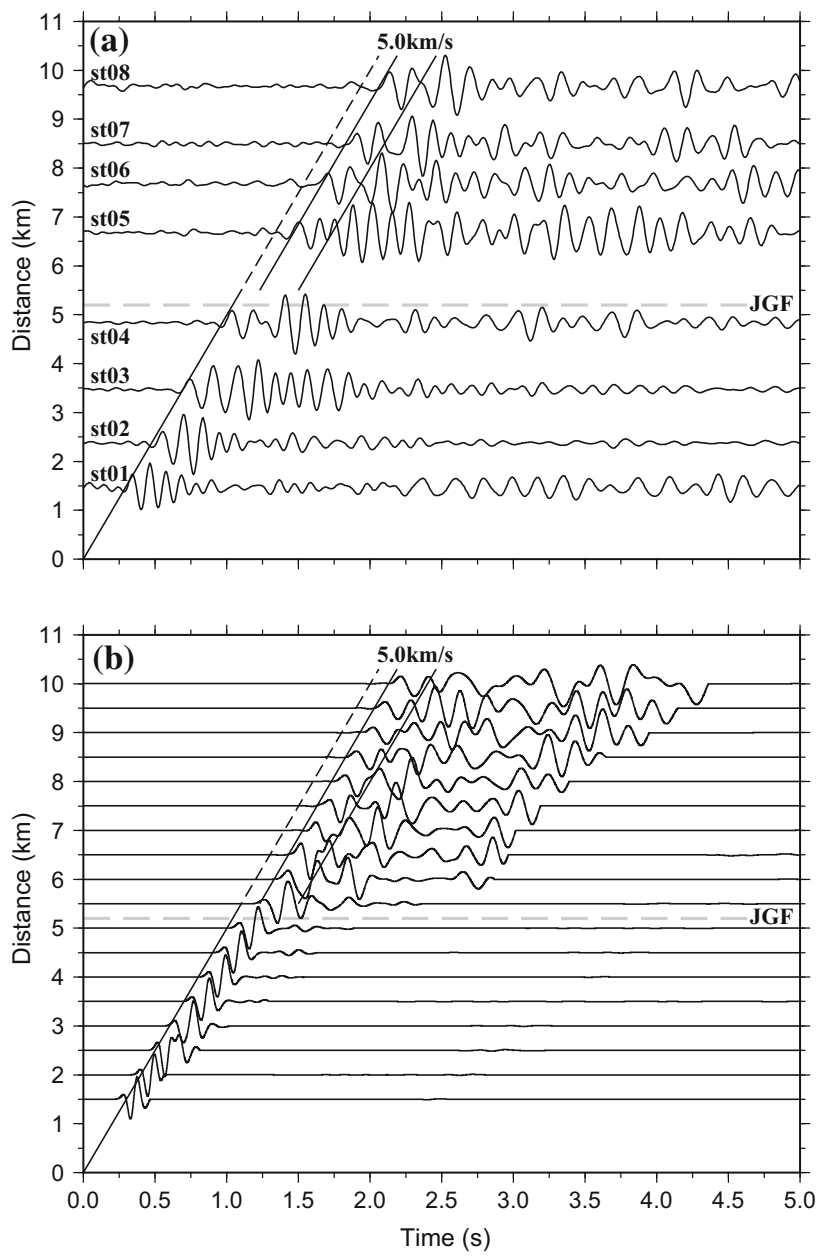

Fig. 4 a Seismic profile observed by portable seismic stations by stacking signals from the ACROSS during the period of February 1, 2010 to April 30, 2011. b Synthetic seismic profile calculated from the background velocity model shown in Fig. 5

process in the epicentral area of the Wenchuan earthquake. In this section, we carry out forward modeling to identify the possible distribution of velocity change.

\subsection{Observed seismic profile}

A seismic profile recorded by portable stations was shown in Fig. 4a. The seismic profile was generated with the similar process as Yang et al. $(2010,2013)$ but for a longer operation time (February 1, 2010 to April 30, 2011). It can be drawn from Fig. 4a: (1) the apparent velocity of the first arrival $P$ wave is $\sim 5.0 \mathrm{~km} / \mathrm{s}$ on both sides of the fault zone, and there is a time delay of $\sim 0.12 \mathrm{~s}$ that exists in $\mathrm{P}$ wave across the fault zone. The time delay is suggested to be the presence of the fault; (2) a secondary P phase arrives $\sim 0.27 \mathrm{~s}$ after the first $\mathrm{P}$ phase can be identified in stations close and cross the fault (st04-st08), which has a similar apparent velocity as first arrival $\mathrm{P}$ phase. Since the secondary phase has a larger SNR than first arrival P phase, 


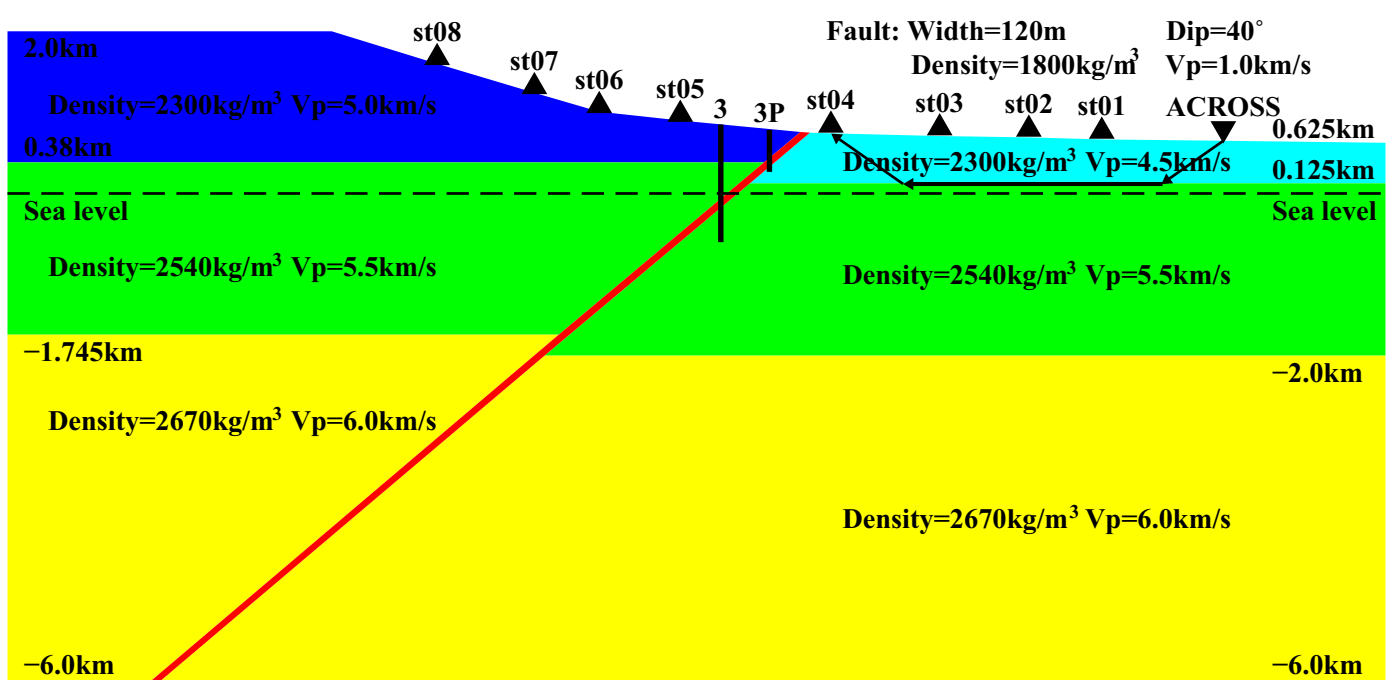

Fig. 5 Background velocity used in the forward modeling. The thickness, density, and P wave velocity are labeled in each layer. The fault geometry is labeled in the top right, and the dashed line indicates the sea level, source and receivers are marked with inverted and normal triangles, respectively. Refraction surveys are the schematic path of seismic rays. WFSD main and pilot holes are labeled with WFSD 3 and 3P, respectively

Yang et al. (2010) measured coseismic travel time delay with the phase.

\subsection{Forward modeling}

Our study area is located in middle part of Longmenshan fault zone, where numerous tomographic studies has been carried out (e.g., Wang et al. 2007; Wang et al. 2009a, b; Lei et al. 2009). Recently, a high resolution seismic reflection survey (Fig. 1a) was conducted by $\mathrm{Xu}$ et al. (2012). Those models suggest that the P-wave velocity of shallow layer on the west side of Jiangyou-Guanxian fault is $\sim 5.0 \mathrm{~km} / \mathrm{s}$, while the velocity on the east side is $\sim 4.5 \mathrm{~km} / \mathrm{s}$. The thickness of unconsolidated layer ranges from 0 to $1 \mathrm{~km}$, and the depth of upper crust is estimated $\sim 3.0 \mathrm{~km}$ in our observed area. Providing detailed velocity structures, the above surveys are unable to evaluate the fine structure of the fault zone. Recently by analyzing core sample and logging data of WFSD No. 3 hole, Yang et al. (2012) suggested that during the period that the dip angle of Jiangyou-Guanxian fault is $\sim 38^{\circ}-46^{\circ}$, and thickness of the fracture zone should be $\sim 126.03 \mathrm{~m}$.

Combing the results from seismic survey and drill, we established a background 2-D model (Fig. 5). The study region is divided into three parts: the hanging wall, the footwall, and the fault. The hanging and foot walls are modeled with three horizontal layers (Fig. 5), and the fault zone is modeled with a low velocity zone with $v_{\mathrm{p}}$ $\sim 1.0 \mathrm{~km} / \mathrm{s}$, dip angle $40^{\circ}$, and thickness $\sim 120 \mathrm{~m}$. We were unable to determine the S-wave velocity from seismic reflection data and we simply assigned the S-wave velocity as $v_{\mathrm{p}} / 1.73$, and the density is taken from Tang et al. (2012).
Our model is consistent with the velocity and thickness of San Andreas fault zone observed from fault zone trapped wave by Li et al. (1997).

We used the Legendre spectral element method (e.g., Komatitsch and Tromp 1999; Liu 2006) in the forward modeling; this method combines high accuracy and fast convergence of the Spectral Method with the flexibility in boundary structure processing of the finite element method, and was widely used from local to global scale. An explosive type of Ricker wavelet with dominant frequency of $8 \mathrm{~Hz}$ was used as input source time function. The top of the model is set as free boundary, while the other three borders are assigned as absorbing boundary. The location of source is settled according to its actual relative position, and receivers are evenly distributed on the surface of model with interval of $0.1 \mathrm{~km}$.

In the forward modeling, we managed to fit the travel time of dominant phases with relative amplitude radiated from the ACROSS. The synthetic seismic profile of the background model (Fig. 5) is shown in Fig. 4b. Ignoring the high amplitude surface wave in Fig. $4 \mathrm{~b}$, the synthetic profile catches main features of the observed profile (Fig. 4a). The first $P$ wave travels at an apparent velocity $\sim 5.0 \mathrm{~km} / \mathrm{s}$ and secondary $\mathrm{P}$ phase $\sim 0.27 \mathrm{~s}$ later than the first $\mathrm{P}$ wave. The reasonable match between synthetic (Fig. 4b) and observed (Fig. 4a) profiles validates our forward model (Fig. 5).

\subsection{Relative change in travel time simulation}

There are two most common interpretations of the coseismic velocity change. Some are willing to argue that 


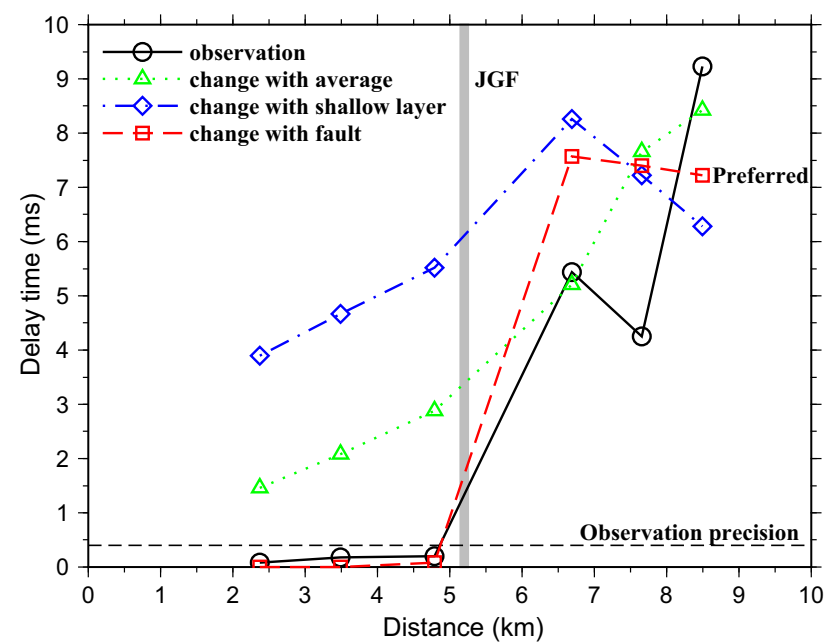

Fig. 6 Observation and predicted travel time delay from three different verified velocity models. See context for more detail

bypassing large amplitude waves may cause strong shaking and loose the sediment resulting in velocity drop (e.g., Schaff and Beroza 2004; Brenguier et al. 2008; Sawazaki et al. 2009; Wu et al. 2009; Takagi et al. 2012). Moreover, Takagi et al. (2012) considered that the velocity change caused by the static stress changes might be masked by the larger effect of the strong ground motion produced by an earthquake. While others tend to attribute observed coseismic velocity changes to static stress releases in fault zones (e.g., Li et al. 2007; Cheng et al. 2010).

We consider three different types of velocity change relative to the background model (Fig. 5): (1) bulk velocity changes, we decrease the velocity of the whole background model (Fig. 5); (2) surface velocity change, just decrease the velocities of uppermost layers of the hanging and foot walls, and the rest of the model keep fixed; and (3) fault zone weakening, the velocities of the $120-\mathrm{m}$ thick fault zone are decreased.

We measured the travel time delay of $\mathrm{P}$ wave by crosscorrelating the waveforms calculated from three modified models with that calculated from background model. The corresponding travel time delay from three different seniors is shown in Fig. 6. All the synthetic results reproduce the observed travel time delay (4-9 ms) observed from the hanging wall stations (st05-st07), and the velocity changes of three modified models are decreased by $0.4 \%$, $0.7 \%$, and $2.0 \%$, respectively. While only the fault zone weakening model predicts the spatial distribution of the travel time delay. Consistent with the intuitive envisioning, the travel time delay gradually increases with the offset for the bulk velocity change model (dotted line in Fig. 6), and for the surface velocity change senior, all the travel time delay are larger than $4 \mathrm{~ms}$.

\section{Discussion}

Even our background model is well-constrained by geological survey and drilling data, there still exists some nonuniqueness in our forward modeling, e.g., trade-off between thickness and velocity (or velocity change). However, we are focusing on travel time delay caused by the relative change of the media, assuming that the possible non-uniqueness will not affect our main conclusions.

As demonstrated by Yang et al. (2010), the precision of travel time delay measurement in this experiment is estimated $\sim 0.4 \mathrm{~ms}$, any delay larger than this value should be detectable. We did not observe any linear tendency of the travel time delay on either sides of the fault, the bulk velocity change senior is at least like the case. Although the surface velocity change model failed to model the observed travel time delay, we are not excluding the surface velocity change induced by seismic wave passing through. The velocity changes in the sediment layer are usually taken as the main cause of observed coseismic velocity change (e.g., Schaff and Beroza 2004; Takagi et al. 2012). In our experiment area, the sediment layer is usually no thicker than $50 \mathrm{~m}$, which is much shorter than the ray path and the subtle change in the sediment layer that may be undetectable with current experiment configuration.

We proposed a $2.0 \%$ velocity decrease within the fault zone which is much larger than most previous observations (e.g., Schaff and Beroza 2004; Cheng et al. 2010). However, by utilizing repeating explosions and earthquakes, $\mathrm{Li}$ et al. (2007) confirmed a velocity decrease of $1.2 \%-2.5 \%$ in the San Andreas fault zone, which is consistent with our model. Earlier seismic observation and laboratory (e.g., Scholz et al. 1973; Terashima 1974) also suggested coseismic velocity decrease with a similar or higher amplitude.

The velocity decrease is likely to be caused by the coseismic static stress release. To evaluate the stress drop in our experiment site, we first relocated the earthquake. The $M_{\mathrm{s}} 5.5$ earthquake was relocated by including portable stations using method of Fang et al. (2011). The epicenter is similar with that provided by China Earthquake Networks Center (CENC), while the focal depth decreases from $24 \mathrm{~km}$ to $\sim 16.6 \mathrm{~km}$. The static stress drop of a magnitude 5.5 earthquake is estimated from 30 to $50 \mathrm{MPa}$ at the focal center (e.g., Abercrombie 1995). And the corresponding static coseismic stress change at the shallow layer within Jiangyou-Guanxian fault zone is estimated to be 7,700-12,500 Pa (e.g., Niu et al. 2008).

The stress-induced velocity change is usually attributed to the opening and closing of existing cracks in the rock. A large number of investigations showed that the stress dependence of seismic wave velocity ranges from $10^{-9}$ to $10^{-6} \mathrm{~Pa}^{-1}$ (e.g., Birch 1960, 1961; Simmons 1964). The stress sensitivity is affected by several factors such as crack density, 
fluid, and applied stress (e.g., Wang et al. 2008). A 2.0 \% velocity change at stress drop of $0.0077-0.0125 \mathrm{MPa}$ corresponds to a stress sensitivity of $\sim 10^{-6} \mathrm{~Pa}^{-1}$. Stress sensitivity of $\sim 10^{-6} \mathrm{~Pa}^{-1}$ is little bit larger than the previous results from laboratory and field measurements (e.g., Simmons 1964; Niu et al. 2008), but consistent with the stress sensitivity of velocity perturbation from the passive and active source data in this region (Chen et al. 2014) and the sensitivity of fractured zone or surface sediments in others (e.g., Silver et al. 2007; Wang et al. 2008). Coring samples from the WSFD No. 3 well indicate that the fault zone is not only heavily fractured but also highly saturated with water (e.g., Yang et al. 2012). High crack density, high pore pressure, and existence of fluid all help in enhancing the stress sensitivity (e.g., Wang et al. 2008).

\section{Conclusions}

In this paper, we conduct a series of forward modeling by fitting the previously observed travel time delay to investigate the distribution of coseismic velocity change. Our results suggest the observed velocity change is best explained by a $2.0 \%$ velocity decrease localized within the $120 \mathrm{~m}$ wide fault zone. And the fault zone velocity decrease is supposed to be a result of coseismic stress release. However, our results do not exclude the dynamic stress change induced shallow surface change, which will be further investigated by follow-up studies.

Acknowledgments We thank the Instrument Center of China Seismic Array (China Earthquake Administration) for providing instruments and Dr. Lihua Fang for helping in earthquake relocation. The manuscript benefits from useful comments by Prof. Niu Fenglin. This study are supported by China Natural Scientific and Technological Support Projects (Wenchuan Fault Scientific Drilling) and National Natural Scientific Foundation of China (Grant No. 41204047).

\section{References}

Abercrombie RE (1995) Earthquake source scaling relationships from -1 to $5 \mathrm{ML}$ using seismograms recorded at $2.5-\mathrm{km}$ depth. J Geophys Res 100(B12):24015-24036

Alekseev AS, Chichinin IS, Korneev VA (2005) Powerful lowfrequency vibrators for active seismology. Bull Seismol Soc Am 95:1-17

Aster RC, Shearer PM, Berger J (1990) Quantitative measurements of shear wave polarizations at the Anza Seismic Network, southern California: implications for shear wave splitting and earthquake prediction. J Geophys Res 95:12449-12473

Birch F (1960) The velocity of compressional waves in rocks to 10 kilobars, part 1. J Geophys Res 65:1083-1102

Birch F (1961) The velocity of compressional waves in rocks to 10 kilobars, part 2. J Geophys Res 66:2199-2224

Brenguier F, Campillo M, Hadziioannou C, Shapiro NM, Nadeau RM, Larose E (2008) Postseismic relaxation along the San
Andreas fault at Parkfield from continuous seismological observations. Science 321:1478-1481

Chen HC, Ge HK, Niu FL (2014) Semiannual velocity variations around the $2008 M_{\mathrm{w}} 7.9$ Wenchuan Earthquake fault zone revealed by ambient noise and ACROSS active source data. Earthq Sci. doi:10.1007/s11589-014-0089-5

Cheng X, Niu FL, Wang BS (2010) Coseismic velocity change in the rupture zone of the $2008 M_{\mathrm{w}} 7.9$ Wenchuan earthquake observed from ambient seismic noise. Bull Seismol Soc Am 100(5B):2539-2550

Fang LH, Wu JP, Zhang TZ, Huang J, Wang CZ, Yang T (2011) Relocation of mainshock and aftershocks of the 2011 Yingjiang $M_{\mathrm{s}} 5.8$ earthquake in Yunnan. Acta Seismol Sin 33(2):262-267 (in Chinese with English abstract)

Haase JS, Shearer PM, Aster RC (1995) Constraints on temporal variations in velocity near Anza, California, from analysis of similar event pairs. Bull Seismol Soc Am 85:194-206

Ikuta R, Yamaoka K (2004) Temporal variation in the shear wave anisotropy detected using the accurately controlled routinely operated signal system. J Geophys Res 109:B09305. doi:10. 1029/2003JB002901

Kanamori H, Fuis G (1976) Variation of P wave velocity before and after the Galway Lake earthquake $\left(M_{\mathrm{L}}=5.2\right)$ and the Goat Mountain earthquakes $\left(M_{\mathrm{L}}=4.7\right), 1975$, in the Mojave desert, California. Bull Seismol Soc Am 66:2027-2037

Komatitsch D, Tromp J (1999) Introduction to the spectral element method for three-dimensional seismic wave propagation. Geophys J Int 139:806-822

Lei JS, Zhao DP, Su JR, Zhang GW, Li F (2009) Fine seismic structure under the Longmenshan fault zone and the mechanism of the large Wenchuan earthquake. Chin J Geophys 52(2):339-345 (in Chinese with English abstract)

Li YG, Ellsworth WL, Thurber CH, Malin PE, Aki K (1997) Observations of fault-zone trapped waves excited by explosions at the San Andreas fault, central California. Bull Seismol Soc Am 87:210-221

Li YG, Chen P, Cochran ES, Vidale JE (2007) Seismic velocity variations on the San Andreas fault caused by the 2004 M6 Parkfield Earthquake and their implications. Earth Planets Space 59:21-31

Li HB, Wang ZX, Fu XF, Hou LW, Si JL, Qiu ZL, Li N, Wu FY (2008) The surface rupture zone distribution of the Wenchuan earthquake $\left(M_{\mathrm{s}} 8.0\right)$ happened on May 12th, 2008. Geol China 35(5):803-813 (in Chinese with English abstract)

Liu QY (2006) Spectral-element simulations of three-dimensional seismic wave propagation and applications to source and structural inversions. Ph. D. Dissertation, California Institute of Technology. Publication Number: AAI3235583, ISBN: 9780542892585

McEvilly TV, Johnson LR (1974) Stability of P and S velocities from central California quarry blasts. Bull Seismol Soc Am 64:343-353

Nadeau RM, Antolik M, Johnson PA, Foxall W, McEvilly TV (1994a) Seismological studies at Parkfield III: microearthquake clusters in the study of fault-zone dynamics. Bull Seismol Soc Am 83:247-263

Nadeau RM, Karageorgi ED, McEvilly TV (1994b) Fault-zone monitoring with repeating similar microearthquakes: a search for the Vibroseis anomaly at Parkfield. Seismol Res Lett 65:69

Niu FL, Silver PG, Daley TM, Cheng X, Majer EL (2008) Preseismic velocity changes observed from active source monitoring at the Parkfield SAFOD drill site. Nature 454:204-208

Peng ZG, Ben-Zion Y (2006) Temporal changes of shallow seismic velocity around the Karadere-Duzce branch of the north Anatolian fault and strong ground motion. Pure appl Geophys 163:567-599 
Poupinet G, Ellsworth WL, Frèchet J (1984) Monitoring velocity variations in the crust using earthquake doublets: an application to the Calaveras fault, California. J Geophys Res 89:5719-5731

Rohrbach E, Liu L, Wang L (2013) Variation in seismic velocity and attenuation associated with seismogenesis: a numerical verification using ambient noise. Tectonophysics 584:54-63

Rubinstein JL, Uchida N, Beroza GC (2007) Seismic velocity reductions caused by the 2003 Tokachi-Oki earthquake. J Geophys Res 112:B05315. doi:10.1029/2006JB004440

Sawazaki K, Sato H, Nakahara H, Nishimura T (2009) Time-lapse changes of seismic velocity in the shallow ground caused by strong ground motion shock of the 2000 western-Tottori earthquake, Japan, as revealed from coda deconvolution analysis. Bull Seismol Soc Am 99(1):352-366

Schaff DP, Beroza GC (2004) Coseismic and postseismic velocity changes measured by repeating earthquakes. J Geophys Res 109:B10302. doi:10.1029/2004JB003011

Scholz CH, Sykes LR, Aggarwal YP (1973) Earthquake prediction: a physical basis. Science 181:803-810

Semenov AN (1969) Variation in the travel time of transverse and longitudinal waves before violent earthquakes. Bull Acad Sci USSR, Phys Solid Earth 3:245-248

Silver PG, Daley TM, Niu FL, Majer EL (2007) Active source monitoring of cross-well seismic travel time for stress-induced changes. Bull Seismol Soc Am 97(1B):281-293

Simmons G (1964) Velocity of shear waves in rocks to 10 kilobars 1. J Geophys Res 69:1123-1130

Takagi R, Okada T, Nakahara H (2012) Coseismic velocity change in and around the focal region of the 2008 Iwate-Miyagi Nairiku earthquake. J Geophys Res 117:B06315. doi:10.1029/ 2012JB009252

Tang XG, You SS, Hu WB, Yan LJ (2012) The crustal density structure underneath Longmenshan fault zone. Seismol Geol 34(1):28-38 (in Chinese with English abstract)

Terashima $\mathrm{T}$ (1974) Change of $V_{\mathrm{p}} / V_{\mathrm{s}}$ before the large earthquake of April 1, 1968 in Hyuganada, Japan. Bull Int Inst Seismol Earth Eng 12:17-29

Wang CY, Han WB, Wu JP, Lou H, Chan WW (2007) Crustal structure beneath the eastern margin of the Tibetan Plateau and its tectonic implications. J Geophys Res. doi:10.1029/ 2005J13003873
Wang BS, Zhu P, Chen Y, Niu FL, Wang B (2008) Continuous subsurface velocity measurement with coda wave interferometry. J Geophys Res 113:B12313. doi:10.1029/2007JB005023

Wang HT, Zhuang CT, Xue B, Zhao CP, Zhu ZY (2009a) Precisely and actively seismic monitoring. Chin J Geophys 52(7):1808-1815 (in Chinese with English abstract)

Wang Z, Yoshio F, Pei SP (2009b) Structural control of rupturing of the $M_{\mathrm{w}} 7.92008$ Wenchuan Earthquake. China Earth Planet Sci Lett 279:131-138

Wang BS, Ge HK, Yang W, Wang WT, Wang B, Wu GH, Su YJ (2012) Transmitting seismic station monitors fault zone at depth. EOS, Trans, Am Geophys Union 93(5):49-50

Wu CQ, Peng ZG, Ben-Zion Y (2009) Non-linearity and temporal changes of fault zone site response associated with strong ground motion. Geophys J Int 176:265-278

Xu CF, Tian XF, Jia SX, Liu Z, Liu BJ, Li XM, Liu Y (2012) The fine structure of the upper crust in the Longmenshan central and adjacent areas: artificial seismic exploration results. Recent Dev World Seismol 6:82 (in Chinese)

Yamaoka K, Kunitomo T, Miyakawa K, Kobayashi K, Kumazawa M (2001) A trial for monitoring temporal variation of seismic velocity using an ACROSS system. Isl Arc 10:336-347

Yang W, Ge HK, Wang BS, Yuan SY, Song LL, Jia YH, Li YJ (2010) Velocity changes observed by the precisely controlled active source for the Mianzhu $M_{\mathrm{s}} 5.6$ Earthquake. Chin J Geophys 53(5):1149-1157 (in Chinese with English abstract)

Yang G, Li HB, Zhang W, Liu DL, Si JL, Wang H, Huang Y, Li Y (2012) Features of the Anxian-Guanxian fault zone in Longmenshan area of Sichuan Province: a case study of No. 3 hole of Wenchuan Earthquake fault zone scientific drilling (WFSD-3). Geol Bull China 31(8):1219-1232 (in Chinese with English abstract)

Yang W, Wang BS, Ge HK, Song LL, Yuan SY, Li GY (2013) Characteristics and signal detection method of accurately controlled routinely operated signal system. J China Univ Pet 37(1):50-55 (in Chinese with English abstract)

Zhang Y, Feng WP, Xu LS, Zhou CH, Chen YT (2008) Space-time rupture process of 2008 Wenchuan earthquake. Sci China (Ser D) 38(10):1186-1194 (in Chinese with English abstract) 